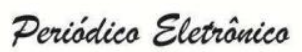

\section{É MACAPÁ-AP SUSTENTÁVEL?}

JOSÉ F. C. FERREIRA ${ }^{1}$

JOSÉ A. TOSTES ${ }^{2}$

LUANA M. VIEIRA ${ }^{3}$

VICTÓRIA R. CARVALHO

\section{RESUMO}

A avaliação da sustentabilidade de municípios é já bem documentada na bibliografia internacional, muito embora seja praticamente inexistente nos municípios da Amazônia, em particular no Estado do Amapá. Utilizam-se indicadores para avaliar o processo de desenvolvimento, valendo-se de uma abordagem multidimensional que contempla diversos aspectos (sociais, ambientais, econômicos, espaciais, culturais e institucionais) e não somente os econômicos. O intuito é providenciar uma ferramenta que subsidie a tomada de decisão e as políticas públicas de desenvolvimento, que responsabilize as empresas, a sociedade civil e as entidades públicas, já que suas atitudes e escolhas têm consequências diretas sobre a sustentabilidade municipal/estadual/nacional/global. Valendo-se de quatro dimensões (político-institucional, econômica, ambiental e sociocultural), este artigo apresenta a avaliação da sustentabilidade de Macapá-AP, Brasil.

Palavras Chave: avaliação da sustentabilidade; indicadores de sustentabilidade; Macapá; Estado do Amapá.

\section{IT MACAPÁ-AP SUSTAINABLE?}

\begin{abstract}
Sustainability assessment of municipalities is already well documented in the international literature, although it is virtually non-existent in the Amazônia municipalities, particularly in the state of Amapá. Indicators are used to evaluate the development process, drawing on a multidimensional approach that incorporates various aspects (social, environmental, economic, spatial, cultural and institutional)

\footnotetext{
${ }^{1}$ Doutor em Geografia e Planeamento Territorial. Pós-doutorando em Desenvolvimento Regional na Universidade Federal do Amapá (Bolsista PNPD-CAPES). Colaborador do CICS.NOVA da FCSH da Universidade Nova de Lisboa. E-mail: zfcofer@gmail.com.

2 Doutor em História e Teoria da Arquitetura. Pós-Doutor em Planeamento Urbano e regional. Professor na Universidade Federal do Amapá. E-mail: tostes.j@hotmail.com

${ }^{3}$ Graduanda do curso de Arquitetura e Urbanismo da Universidade Federal do Amapá. Bolsista de Iniciação Científica. E-mail: luanavieira.ara@gmail.com

${ }^{4}$ Graduanda do curso de Arquitetura e Urbanismo da Universidade Federal do Amapá. Bolsista de Iniciação Científica. E-mail: victoriareis14@gmail.com
} 


\section{Periódica Eletrânica

and not only economic. The aim is to provide a tool that assists decision making and public development policies, that responsabilize companies, social society and public authorities, since their attitudes and choices have direct consequences on the city / state / national / global sustainability. Drawing on four dimensions (political, institutional, economic, environmental and socio-cultural), this article presents the assessment of the sustainability of Macapá-AP, Brazil.

KEYWORDS: Sustainable assessment; Sustainable indicators; MAcapá; State of Amapá.

\section{SE MACAPÁ-AP SOSTENIBLE?}

\section{RESUMEN}

La evaluación de la sostenibilidad de los municipios está bien documentada en la literatura internacional, aunque es prácticamente inexistente en los municipios de la Amazônia, particularmente en el estado de Amapá. Se utilizan indicadores para evaluar el proceso de desarrollo, aprovechando un enfoque multidimensional que incluye diversos aspectos (sociales, ambientales, económicos, espaciales, culturales e institucionales) y no sólo los económicos. El objetivo es proporcionar una herramienta que ayuda a la toma de decisiones y las políticas públicas de desarrollo, para responsabilizar las empresas, la sociedad civil y las autoridades públicas, ya que sus actitudes y decisiones tienen consecuencias directas sobre la sostenibilidad municipal / estadual / nacional / global. Sobre la base de cuatro dimensiones (políticas, institucionales, económicos, ambientales y socio-culturales), este artículo presenta la evaluación de la sostenibilidad de Macapá-AP, Brasil.

Palabras clave: evaluación de la sostenibilidad; indicadores de sostenibilidad; Macapá; Estado de Amapá.

\section{INTRODUÇÃO}

Hoje, o conceito de desenvolvimento sustentável inunda programas, planos, projetos, negócios. Ele está presente em documentos oficiais, nacionais e internacionais, e, para muitos, se apresenta como a possibilidade de se poder alterar a atual situação de "risco". O planeta dá indícios de estar a ficar saturado, com a agravante de que não é mais uma opção remota a possibilidade de entrar em colapso (BOFF, 2013). Enquanto isso, talvez iludidos por uma falsa esperança e por um afã de poder e de riqueza, o ser humano continua a explorar os recursos naturais desenfreadamente, gerando intensos desiquilíbrios no planeta e resíduos que o planeta se mostra, cada vez mais, difícil de absorver e integrar.

O modelo de desenvolvimento, que insiste na produção e no consumo de massa, a sociedade que, mesmo cada vez mais e melhor organizada, ainda está longe de exercer as pressões necessárias para a transformação, e as instituições 


\section{Periódica Eletrânica

públicas, que se preocupam mais com uma gestão imediata e populista do que pensar a médio e a longo prazo, contribuem para que a mudança teime em acontecer.

Do mesmo modo, a sustentabilidade não pode ser vista apenas sob o ângulo do ambiente, da economia ou do social, juntos ou cada um por si. Não basta, por isso, que o desenvolvimento seja apenas economicamente viável, ambientalmente correto e socialmente justo (anos 1990). Esta visão, mesmo que mais cabal do aquela que vê o desenvolvimento apenas como crescimento econômico, é ainda limitada, já que opera em um ambiente de competitividade, sem que se afetem os lucros, não se enfraqueça a competição e não se prejudiquem as inovações tecnológicas (BOFF, 2013).

Neste encalço, precisamos de um outro modo de pensar e de agir mais próximo da harmonia com a natureza e respeito pela vida, sem os quais a nossa sobrevivência, enquanto espécie, está fortemente ameaçada. Não basta pensar somente neste triple botton line, mas é necessário pensar a realidade de forma sistémica, incorporando novos aspectos, dimensões, valores e estratégias.

Embora a sustentabilidade não seja exclusiva do urbano ou do rural, do local ou do global, do aqui e do depois, o certo é que pensar a sustentabilidade demanda um posicionamento em todas as escalas, do local ao global. No entanto, embora não exclusivamente, as cidades pelo seu tamanho, dinâmica, complexidade e impactos negativos sobre o ambiente, requerem uma atenção particular.

Com este artigo, pretende-se refletir sobre Macapá, capital do estado do Amapá, tendo como pano de fundo o conceito de desenvolvimento sustentável. Desde modo, a partir de uma seleção de indicadores que cobrem um vasto role de elementos, em quatro dimensões (político institucional, econômica, ambiental e sociocultural), será feita uma reflexão que se pretende responder ao questionamento do título do artigo. O objetivo principal é perceber, mediante o uso de indicadores, se Macapá é ou não sustentável. Em particular, interessa saber com algum detalhe em que dimensões está a sua maior força ou a sua maior debilidade.

Começaremos por apresentar Macapá no contexto do Estado. Apresentarse-á, em seguida, o conceito de desenvolvimento sustentável, procurando captar os aspectos mais relevantes para esta avaliação, que permitam responder à indagação que a suporta, e obter um resultado final, fruto da combinação de variáveis e 


\section{Periódica Eletrânica

indicadores. A metodologia será apresentada subsequentemente. No final, apresentar-se-ão os resultados e os comentários mais relevantes.

\section{MACAPÁ-AP}

Macapá é a maior cidade e a capital do Estado do Amapá. Em 2014, segundo estimativa do IBGE, apresentava uma população de 446.757 habitantes, apresentando um crescimento de 12,14\%, desde o último censo de 2010 . Todavia, olhando para os últimos 34 anos (1980-2014), a população cresceu 217,69\% (de 140.624 habitantes, em 1980, para os estimados 446.757 habitantes, em 2014).

Este crescimento da população tem-se intensificado a partir dos anos 1980, decorrente, sobretudo, da estadualização do Amapá (1989), mas também de investimentos da União e do capital nacional e internacional - expansão das forças produtivas capitalistas (BECKER, 2001; NASCIMENTO; COUTO; FERREIRA, 2010; SANTOS, 2010; PORTO et al, 2011; SUPERTI; PORTO; MARTINS, 2011), que intensificaram novas procuras pelo urbano e por acesso a determinados bens e serviços, como saúde, educação, emprego e renda. Neste sentido, Macapá tem exercido um poder de atração para as populações de outras cidades do estado e de estados vizinhos (TOSTES, 2007; PORTO, 2010).

O contingente populacional (que continua aumentando) apresenta numerosos desafios às entidades públicas, sobretudo o da gestão de um território complexo em que as infraestruturas urbanas não acompanham esse crescimento. Tostes (2011), observando a situação das cidades do Amapá, salienta que elas constituem espaços urbanos altamente desestruturados, sem políticas eficazes e planejamento fragmentado. Esse tipo de planejamento ocorre somente por que há pressão social e política. Inevitavelmente, um de seus resultados é o surgimento de espaços urbanos informais, com assentamentos em condições desastrosas e incipientes condições de serviços e equipamentos urbanos, como é o caso das ocupações das áreas de ressaca (segundo dados do IBGE, Macapá atingiu, em 2010, 60\% de moradias em áreas irregulares de todo o Estado). Acresce a estas dificuldades a ineficácia do estado (políticas estatais e estaduais), que contribui, sobremaneira, para que estes problemas ocorram ou se exacerbam (SOUZA, 2014). 
Associado ao crescimento populacional e às dificuldades institucionais em acompanhar este crescimento e às de gestão de um território complexo, com notada ausência de planejamento, em detrimento do improviso e da adoção de práticas imediatistas e de curto prazo, faz-se necessário um outro olhar sobre a cidade.

Figura 1 - Mapa de localização de Macapá

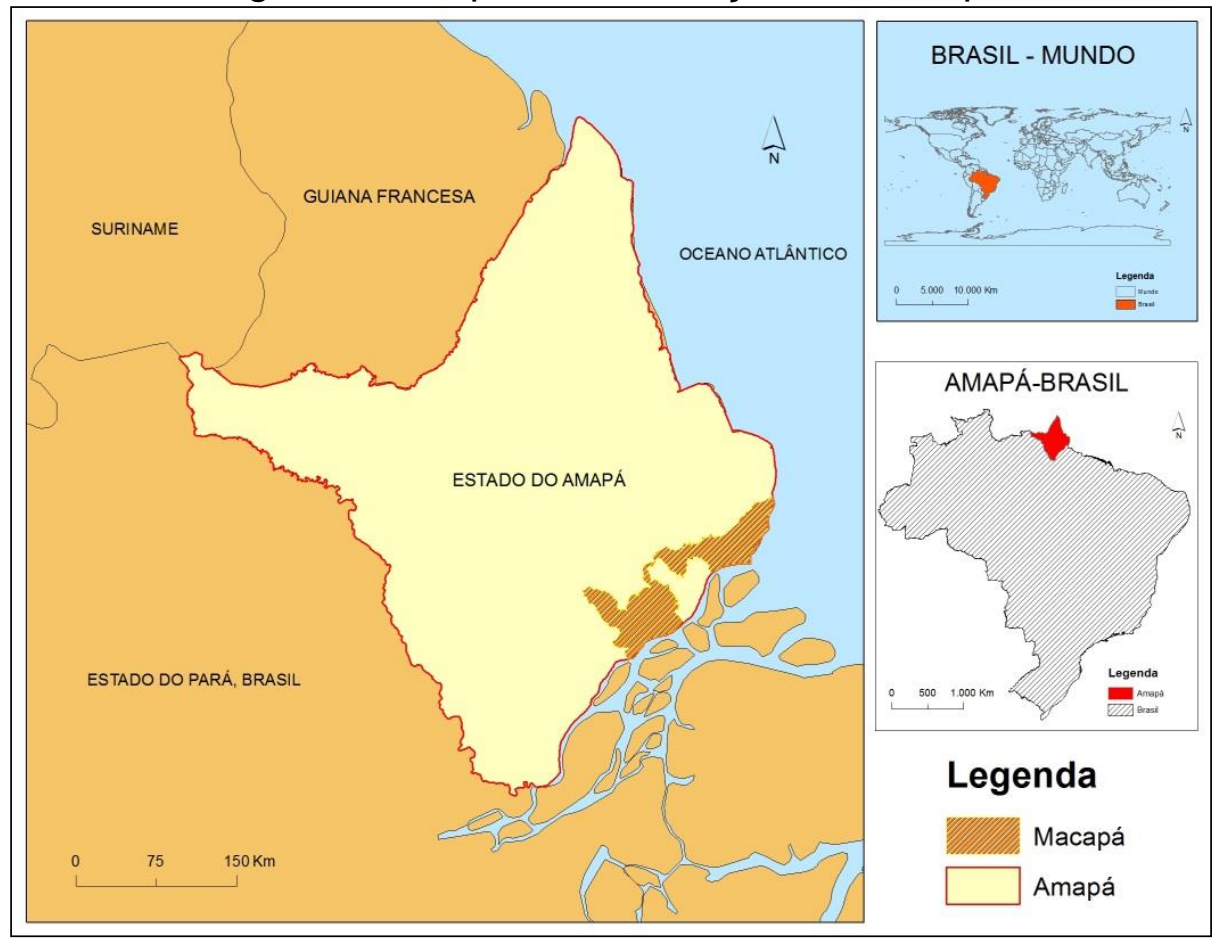

Elaborado pelos autores, 2015. Arcgis 10.0.

\section{CONCEPÇÃO DE DESENVOLVIMENTO SUSTENTÁVEL}

Até ao momento, não existe uma definição comumente aceita de desenvolvimento sustentável. Todavia, a que tem mais eco é a do Relatório Brundtland, onde é definido como o «...que satisfaz as necessidades do presente sem comprometer a capacidade de as gerações futuras satisfazerem suas próprias necessidades.» (CMMAD, 1991), definição consagrada na RIO-92 (SIENA, 2002), e que tem sido alvo de diversas reflexões, em vários âmbitos e em múltiplos quadrantes (sociais, políticos, ambientais e econômicos) (VEIGA, 2008).

Kerk e Manuel (2008), a partir desta supramencionada definição, determinaram as características de uma sociedade sustentável: onde são satisfeitas 
as necessidades da geração presente; não se compromete a capacidade de as futuras gerações satisfazerem as suas próprias necessidades; cada ser humano tem a oportunidade de se desenvolver em liberdade, em uma sociedade equilibrada e em harmonia com o seu ambiente circundante. Deste modo, cada ser humano (1) pode desenvolver-se de uma maneira saudável, (2) obtém educação adequada, (3) vive num ambiente limpo, (4) numa sociedade equilibrada e segura, (5) usa os recursos não renováveis de modo responsável e (6) contribui para um mundo sustentável.

Quando se trata de pensar o desenvolvimento sustentável, Martins (2004) sugere algumas questões a fazer: estas ações satisfazem as necessidades básicas humanas? Promovem a equidade e a justiça social? Comprometem-se com as gerações futuras? Respeitam a autodeterminação dos povos? Respeitam a diversidade cultural e a manutenção do patrimônio ambiental? Promovem a cidadania? Preconizam novos padrões de consumo em harmonia com a natureza?

Wheeler (2004) define desenvolvimento sustentável como aquele que melhora, a longo-prazo, a saúde dos sistemas humano e ecológico. Siena (2002) considera que há três características que a maioria das definições tem em comum: uma condição humana desejável, uma condição do ecossistema desejável e equidade duradoura, entre a presente e as gerações futuras e dentro da presente geração.

Gibson et al (2005), sintetiza a essência do desenvolvimento sustentável em nove características. Ele é (1) um desafio ao pensamento e práticas convencionais; (2) diz respeito ao bem-estar no curto e no longo prazo; (3) percorre os aspectos mais importantes da tomada de decisão; (4) supõe o reconhecimento de ligações e interdependências; (5) tem de ser alcançado num mundo de complexidade e surpresa; (6) reconhece limites invioláveis e infinitas oportunidades para uma inovação criativa; (7) é um conceito vago e impreciso (8) os fins e os meios estão interligados e (9) é universal e dependente do contexto.

Ferreira (2012) define o desenvolvimento sustentável como o processo de transformações que, ocorrendo de forma harmoniosa em várias dimensões (espacial, ambiental, econômica, social, cultural e institucional), almeja a promoção humana integral, a cidadania plena e a equidade social, a paz e a segurança, um 


\section{Periódica Eletrânica

ambiente saudável e ecologicamente equilibrado, no contexto das gerações presentes e futuras e na direção de um mundo sustentável.

Considerando as definições referidas, entre outras, este artigo atende a uma vasta bibliografia sobre indicadores e metodologias para avaliar a sustentabilidade, sejam elas de nível local, regional, nacional e internacional (veja-se HARDI et al, 1995; SELMAN, 1996; SIENA, 2002; ROLDÁN e VALDÊS, 2002; BELLEN, 2004; BRAGA et al, 2004; SILVA, 2006; NADER et al, 2008; KERK e MANUEL, 2008; RAMOS, 2009; MASCARENHAS et al, 2010; PROGRAMA CIDADES SUSTENTÁVEIS, 2012; FERREIRA, 2012, 2013; BOFF, 2013; SANTOS et al, 2014).

Assim sendo, tendo em vista que a pretensão é responder se Macapá é ou não sustentável, vamos ter em conta os aspectos mais importantes inerentes às definições de desenvolvimento sustentável, que vamos agrupar em dimensões, a partir de indicadores e suas variáveis. Para cada uma destas dimensões são selecionadas subdimensões, que têm a ver com os elementos mais relevantes de cada dimensão. São tidos em conta aspectos como a participação, a gestão financeira, gestão urbana, renda, meio ambiente (ar, água, resíduos), saúde, educação, habitação e cultura, que se subdividem em indicadores e estes em variáveis, contemplando um vasto rol de assuntos diretamente conectados com a definição de desenvolvimento sustentável.

Relativamente aos indicadores, embora ainda se discuta o número e tipo a ser utilizados, é comumente aceite a necessidade de fazer medições para aferir o progresso em direção ao desenvolvimento sustentável (BOSSEL, 1999; MORAN et al, 2008; RAMOS, 2009). Com isto, pretende-se prover uma ferramenta de orientação para as políticas públicas de sustentabilidade (TAVARES, 2005). O objetivo é que os indivíduos, grupos, empresas, instituições públicas reconheçam que seus comportamentos e escolhas têm efeitos sobre o estado da sustentabilidade (SIENA, 2002).

\section{METODOLOGIA}

Considerando o objetivo central deste artigo, recorreremos a indicadores de sustentabilidade, ordenados em 4 dimensões (Político-institucional, econômica, ambiental e sociocultural), e várias subdimensões que resultam dos aspectos mais 


\section{Periódica Eletrânica

importantes do conceito de desenvolvimento sustentável. Estas são subsidiadas por indicadores e estes por variáveis.

Tem-se como referência o trabalho de Ferreira $(2012,2013)$, e consideramse outras metodologias que têm este mesmo propósito, como o Índice de Sustentabilidade dos Municípios da Amazônia (ISMA), Ribeiro (2002), que produziu o "Modelo de Indicadores para mensuração do desenvolvimento sustentável da Amazônia”, Kerk e Manuel (2008), Silva, Souza e Leal (2012) e Santos et al (2014) no Índice de Progresso Social da Amazônia Brasileira.

Para o nosso propósito, será atribuído o mesmo peso aos indicadores, que serão padronizados utilizando duas escalas sobrepostas (fig. 2): a escala padrão, que será referência para todos os indicadores (de 0-100, dividida em intervalos de 20), e a escala do indicador, que será elaborada de acordo com a natureza do indicador e terá em conta valores meta ou padrão locais, regionais, nacionais e internacionais, quando os houver.

Figura 2 - Escala do indicador e escala padrão

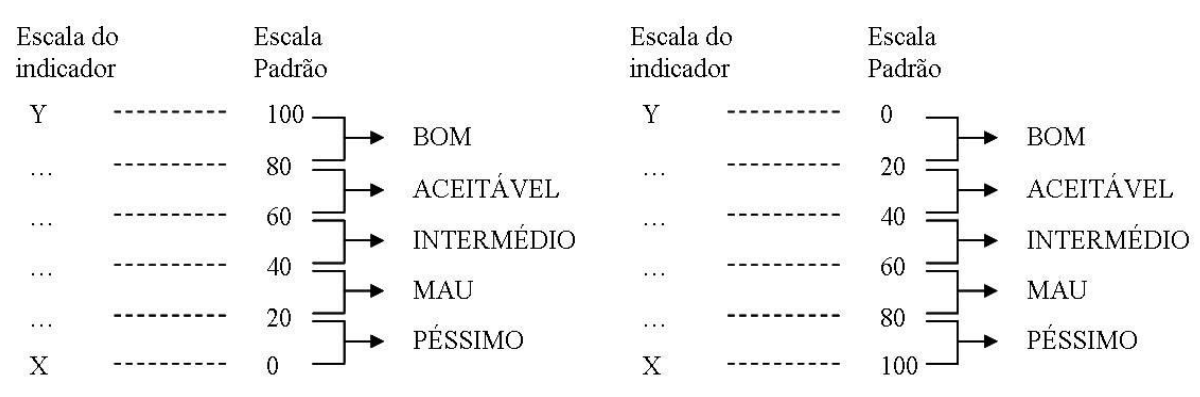

Fonte: Ferreira, 2012.

Com este procedimento, resolve-se uma outra questão importante que é a padronização dos indicadores, já que, como todos têm uma natureza e medida próprias (Siena, 2002), é necessário um procedimento que os possibilite utilizar na mesma unidade de medida.

O cálculo será efetuado através de 2 fórmulas (fig. 3), que permitirão a obtenção de um valor final para Macapá, objeto de reflexão deste artigo. Para a questão dos valores padrão, utilizar-se-á como referência o documento do Programa Cidades Sustentáveis (2012), "Metas de Sustentabilidade para os Municípios Brasileiros (Indicadores de Referência)". 
Figura. 3 - Fórmulas de cálculo

FÓRMULA 1: Pontuação = topo banda da escala padrão - $\{[$ (valor do indicador - valor base da banda do indicador) $\div$ (valor topo da banda do indicador - valor base da banda do indicador)] $\times 20\}$. FÓRMULA 2: Pontuação $=\{[$ (valor do indicador - valor base da banda do indicador $) \div$ (valor topo da banda do indicador - valor base da banda do indicador)] x 20$\}+$ base da banda da escala padrão.

Adaptado de Siena, 2002.

O procedimento é simples e, além de pretender ser de fácil compreensão, pretende ser replicável para outros territórios. Seguindo a apresentação do quadro 1 , o valor final obtido para cada dimensão resulta da média das subdimensões, sendo estas o resultado da média simples dos indicadores que a constituem, os quais resultam da média simples das variáveis pelas quais são compostos. O resultado final pode ser discriminado por dimensão, subdimensão e indicador, permitindo que sejam feitas várias leituras/comparações. O valor dos indicadores é obtido por uma ou mais variáveis (quadro 2). Vale salientar que ao Quadro 2 pode ser possível acrescentar outras variáveis, já que algumas são de difícil acesso.

De acordo com a literatura sobre este tema, os indicadores devem ser relevantes e perceptíveis, transparentes, mensuráveis, representativos do consenso internacional, estar disponíveis, não se sobrepor uns aos outros, ser confiáveis, recentes e regularmente atualizados, permitir fazer comparações e ser limitados em número (BOSSEL, 1999; ROLDÁN e VALDÉS, 2002; SIENA, 2002; BRAGA et al, 2004; KERK e MANUEL, 2008; MASCARENHAS et al, 2010).

\section{RESULTADOS E DISCUSSÃO}

Considerando aos critérios acima referidos, foram utilizadas 61 variáveis, 35 indicadores, 13 subdimensões e 4 dimensões. O resultado é apresentado nos quadros 1 e 2

Quadro 1 - Resultados da avaliação da sustentabilidade por município e dimensão 


\begin{tabular}{|l|c|}
\hline \multicolumn{1}{|c|}{ Dimensão } & Macapá-AP \\
\hline Político Institucional & 42,57 \\
\hline Econômica & 60,49 \\
\hline Ambiental & 27,33 \\
\hline Sociocultural & 61,94 \\
\hline \multicolumn{2}{|c|}{ Valor médio } \\
\hline \multicolumn{2}{|c|}{48,08}
\end{tabular}

Elaborado pelos autores, 2015. 


\section{Periódica Eletrânica

Quadro 2. Dimensões, subdimensões, indicadores e variáveis utilizadas

\begin{tabular}{|c|c|c|c|c|c|}
\hline DIMENSÃO & SUBDIMENSÃO & INDICADOR & VARIÁVEL & FONTE & ANO \\
\hline \multirow{11}{*}{$\begin{array}{l}\text { Polfico- } \\
\text { Insthoinal }\end{array}$} & \multirow{2}{*}{ Padficipação } & Captel Sorial & 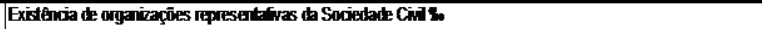 & BGE & 2010 \\
\hline & & Govemanģa & Existencia te consthos muripais paitinos $\mathbf{N}$ & BGE Mni: & 2010 \\
\hline & Dielus infvituais & Diversibent partitivia & 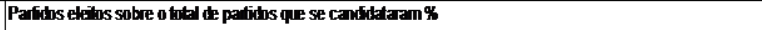 & ISE & 2013 \\
\hline & \multirow[b]{2}{*}{ Gestān Admuistrativa } & \multirow{2}{*}{ Quabidate do Quadro Funcinal } & Nimero \& sevidures pir mi hatitantes so & BGE Mni: & 2010 \\
\hline & & & 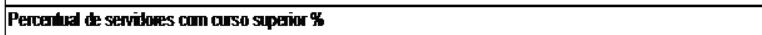 & BGE Unir. & 2010 \\
\hline & \multirow{4}{*}{ Gestân Financeia } & Capacitate de arecahạân & 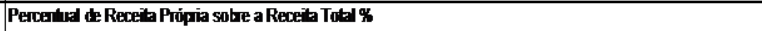 & STMFNBFA & 2010 \\
\hline & & Capacilate de twestimato & Despesas com livesimeitus sobre a Despesa Realiza由 \% & SINF NBRA & 2010 \\
\hline & & \multirow[b]{2}{*}{ Sanile franceira } & Sulfiência de Caxa \% & SINAFMBA & 2010 \\
\hline & & & 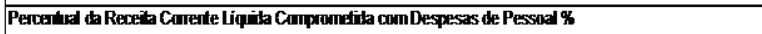 & STNFNBRA & 2010 \\
\hline & & Caradteisicizas Uhbanas & Cararteristicas do eltomo & BGE & 2010 \\
\hline & Gestan Uibana & Motrifate Utbana & Nimero \& An arbus so & Dendran & 2012 \\
\hline \multirow{10}{*}{ Econhmica } & \multirow{10}{*}{ Econamia e Renta } & Nivel \& Renta & Rence per capta Rs & BGE & 2010 \\
\hline & & Desemprego & Taxa \& desocupayăāo - 10 anos ou mais anos & BGE & 2010 \\
\hline & & Designalbe & Indire de Gini & BGE & 2010 \\
\hline & & \multirow{4}{*}{ Vuherabidale } & 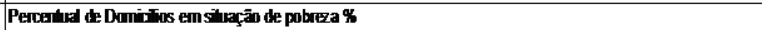 & BGE-CaIso & 2010 \\
\hline & & & Percatayen \& vuherávés à pobrza \% & BGE & 2010 \\
\hline & & & 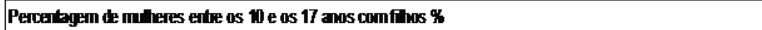 & BGE & 2010 \\
\hline & & & 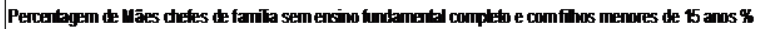 & PNUD & $\mathbf{2 0 1 3}$ \\
\hline & & \multirow{3}{*}{ Divamismo Econfmico } & Evolugäo de Empregus Foumais 201082010?\% & RALS & 2010 \\
\hline & & & Mékla de Crescimento do PB no úlimo tï̈ño ?\% & BGE & 2010 \\
\hline & & & PB per capta, 2010, RS & BGE & 2010 \\
\hline \multirow{14}{*}{ Ambiental } & \multirow{14}{*}{ Mein Ambiente } & \multirow{3}{*}{ Saneankilo básico } & 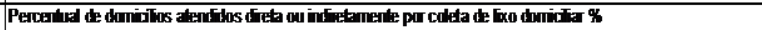 & BGE CBNSO & 2010 \\
\hline & & & 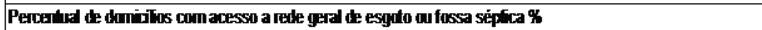 & BGE CBNSO & 2010 \\
\hline & & & 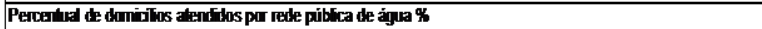 & BGE CBNSO & 2010 \\
\hline & & \multirow{2}{*}{ Gestav Anbintal } & Eletwitute da Estrutura de Gestao Ambiental Noro & BGE Mni: & 20199 \\
\hline & & & 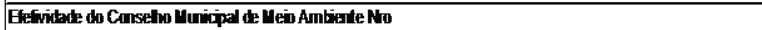 & BGE Mni: & 20109 \\
\hline & & \multirow{3}{*}{ 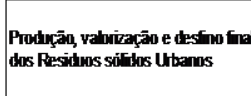 } & Resibuos sititus cum destino a atero \% & sint & \\
\hline & & & Taxa \& cobehtra da colke seltiva & SNES & 2012 \\
\hline & & & Residuos recollidos stefivanertepur hatitante & sint & \\
\hline & & & 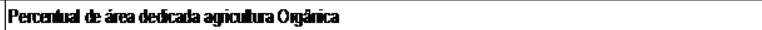 & sint & \\
\hline & & & Áreas Prutejitas & MASONSA & 2011 \\
\hline & & 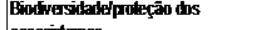 & 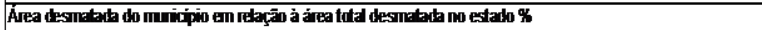 & NPE-PRODES. & 2010012010 \\
\hline & & & Desperticio de àjua & Moid & 2012 \\
\hline & & & Äreas degratadas & MPE & 2012 \\
\hline & & Quchidade do Ar & 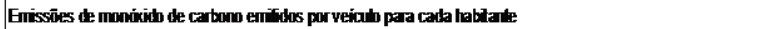 & BGE & 2013 \\
\hline & & Langevitude & Tinlice de Esperanca de vich an nascer, 2010, Non de Anos & BGE- Censo & 2010 \\
\hline & & Mortadidale htanti & 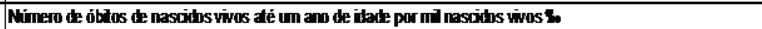 & BGE-Detasis & 20110 \\
\hline & & & Estabdecimalus de Saide por mil habitates so & BGE & 20109 \\
\hline & & Equpantinins & 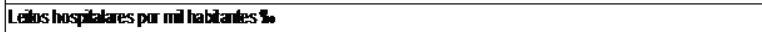 & BGE & 20109 \\
\hline & & Nutiząâ & Subrufliçǟo \% & US & 2012 \\
\hline & Sante & & 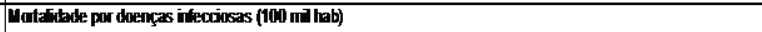 & US & 2012 \\
\hline & & & 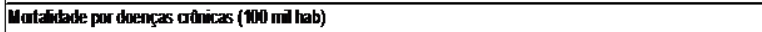 & US & 2010 \\
\hline & & Moutaifade gobal & 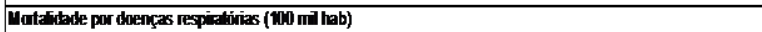 & US & 2012 \\
\hline & & & Suivido (N10 mil hab) & US & 2012 \\
\hline & & Obesibat & Obesitade \% & us & 2012 \\
\hline & & & Populaçāo ätabtizada \% & BGE & 2010 \\
\hline & & Escolainale & Perceatud te pessuas de 25 anos ou mais con supaior completo $\%$ & BGE & 2010 \\
\hline & & & 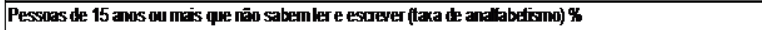 & BGE-CaIso & 2010 \\
\hline Socinalural & Educagäa & & Thise de Aprovełameito do Ersino Básico - IDE & MECNP & 2011 \\
\hline & & Quevilade do Ersino & 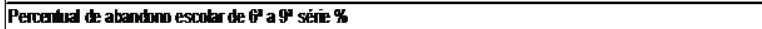 & MEC inep & 2011 \\
\hline & & & Perceltual te abanhbno escolar no ensino mébíno \% & MEC inep & 2011 \\
\hline & $\ln _{0}$ & reme & 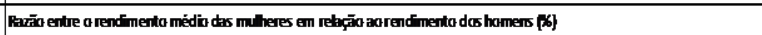 & BGE & 2010 \\
\hline & Genero & Geneto & Videncia contra mithe (1010 mi hab) & US & 2012 \\
\hline & 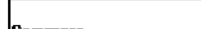 & Ciminalitede & 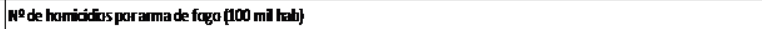 & MGE & 2010 \\
\hline & 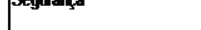 & Trensto & 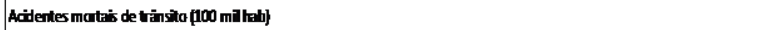 & MGE & 2011 \\
\hline & & & 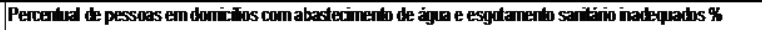 & BGE & 2010 \\
\hline & Hotming & Quichitate habiacinal & 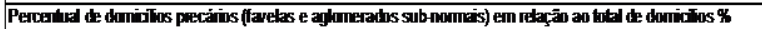 & BGE-Censo & 2010 \\
\hline & & $\begin{array}{l}\text { Estrutura de Gestio para pitticas } \\
\text { habtarimais }\end{array}$ & 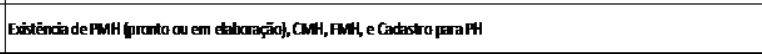 & BGE Mnix & 2011 \\
\hline & Gulura & Infraestumpa ailhral & 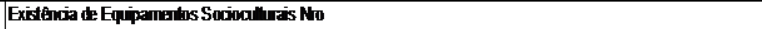 & BGE Mni: & 20109 \\
\hline & & Intemet & Conexão de dahss de intenet mived $\%$ & Anatd & 20122013 \\
\hline & 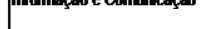 & Vaz & 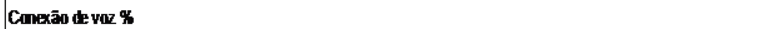 & Anated & 20122013 \\
\hline
\end{tabular}

Elaborado pelos autores, 2015 
Figura. 4 - Resultado da Avaliação da Sustentabilidade de Macapá

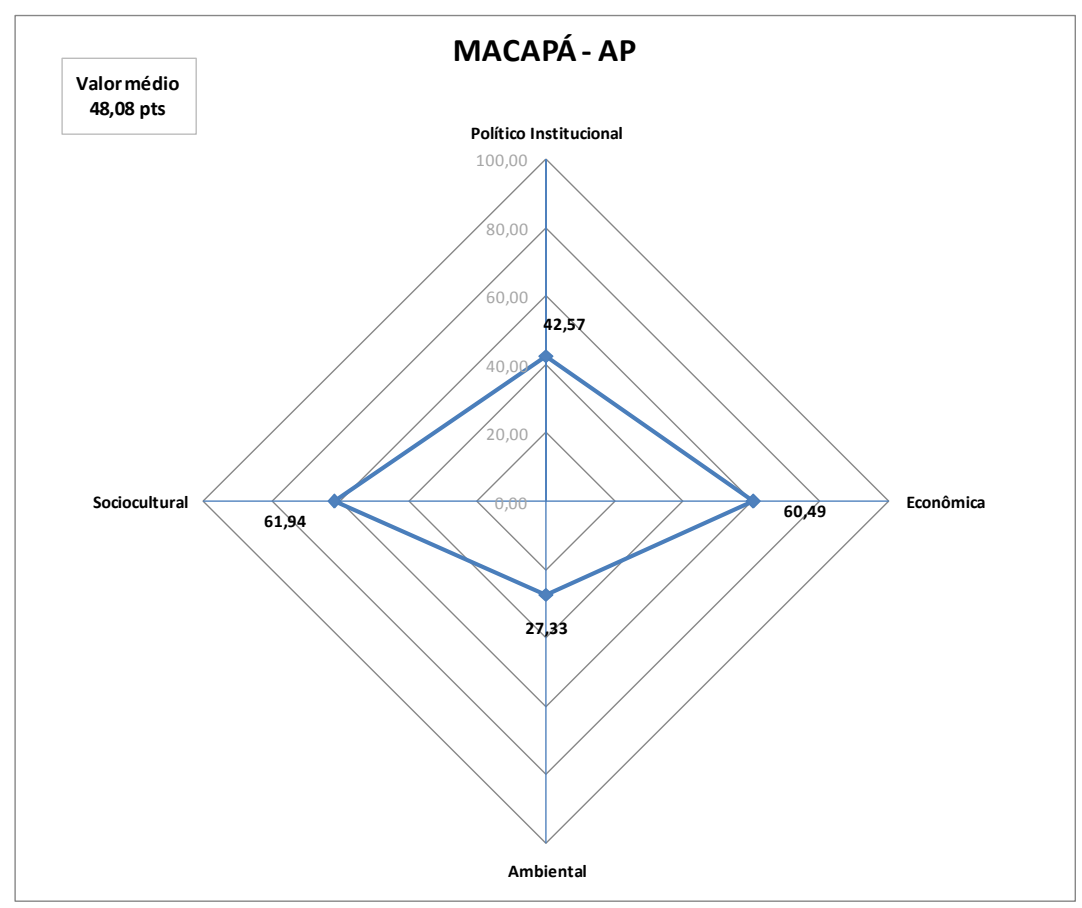

Elaborado pelos autores, 2015

No final desta avaliação em que foram utilizadas 61 variáveis referentes a 35 indicadores, o resultado final médio das 4 dimensões é de 48,08 pontos para Macapá, capital do Estado do Amapá. Considerando a escala padrão, fig. 2, podemos afirmar que Macapá se situa em uma posição intermédia (entre os 40 e os 60 pontos), muito próximo dos 50 pontos, centro da classe.

Importa, neste momento, evidenciar que se trata de uma avaliação pluridimensional, daí o extenso número de variáveis, sendo que este quadro está ainda em aberto, uma vez que podem ser utilizadas outras variáveis, quando estiverem disponíveis à unidade territorial município.

Neste contexto, cabe, ainda, um esclarecimento. Quando se atenta ao quadro 2, na dimensão ambiental, subdimensão "Meio Ambiente", indicador "produção, valorização e destino final dos resíduos sólidos urbanos", podemos constatar que apenas uma variável tem valor "Taxa de cobertura da coleta seletiva", sendo que as outras duas não os possuem, ainda.

Do mesmo modo, também no indicador "Biodiversidade/proteção dos ecossistemas" a variável "Percentual de área dedica a agricultura orgânica" não tem valor. Estamos certos que a ausência de valores para estas variáveis condicionou o 


\section{Periódica Eletrânica

resultado final, sobretudo o que se refere à dimensão ambiental, o valor mais baixo das dimensões para Macapá.

A razão de ser desta opção é a relevância destas variáveis, já que as questões ligadas ao saneamento urbano, entre as quais assume particular acuidade os resíduos sólidos urbanos (recolha, tratamento, valorização e destino final), são de extrema pertinência para a sustentabilidade urbana. Assim, o fato de ainda não existirem valores para mensurá-las não lhes tira a importância.

Num município onde a grande maioria do esgoto não é tratado, o abastecimento de água é feito em condições precárias, sem tratamento e valorização dos resíduos (tem apenas um aterro controlado) e sem produção de alimentos em condições de proteção do meio ambiente (agricultura orgânica), utilizar variáveis para as quais não existem valores, essencialmente, porque as atividades a que se referem essas variáveis não são realizadas, poderá suscitar alguma confusão no leitor.

$\mathrm{Na}$ verdade, havia duas opções. A primeira delas, a de não utilizar variáveis para as quais não existe um valor. Com esta, a dimensão ambiental não refletiria a realidade e apresentaria resultados, significativamente, melhores. A segunda, a de utilizar as variáveis mesmo sem um valor. Por nos parecer a opção mais ajustada, foi utilizada esta segunda, sabendo, à partida, que poderia diminuir o valor final da dimensão, mas com a convicção de que espelha melhor a realidade deste município amazônico. A este respeito, não deixa de ser interessante o fato de o estado do Amapá ser um dos estados mais protegidos do País com $72 \%$ da sua área sob proteção, logo um enorme contrassenso. Embora esta opção não se constate em outras avaliações, decidimos utilizá-la pelo que antes se referiu.

Quanto aos resultados, propriamente ditos, há algumas considerações a fazer. A primeira delas vai para a dimensão Político Institucional. Quando os autores que estudam o Amapá se referem aos problemas que mais notadamente se evidenciam no contexto do estado, eles destacam a debilidade das instituições locais. Ora, os resultados desta avaliação, evidenciados na fig. 3, corroboram com esta situação, já que a pontuação é significativamente baixa (42,57 pontos).

Tirando a variável "Mobilidade urbana", com 83,33 pontos, que se refere ao número de ônibus por mil habitantes, as outras têm um desempenho muito baixo. Veja-se, a título de exemplo, as variáveis "Existência de organizações 


\section{Periódica Eletrânica

representativas da Sociedade Civil" (26,12 pontos), "Percentual de servidores com curso superior" (27,09 pontos), "Percentual de Receita Própria sobre a Receita Total" (10,52 pontos), "Despesas com Investimentos sobre a Despesa Realizada" $(3,45$ pontos). Podemos perceber que as debilidades são de ordem diversa, com as menores pontuações com as mais acentuadas a incidir na subdimensão "Gestão financeira".

No outro extremo, a dimensão ambiental, em parte pelas razões antes assinaladas, tem a menor pontuação de Macapá (27,33 pontos). Na verdade, os indicadores acabem por mostrar a realidade, nua e crua, tal como a vivencia quem mora em Macapá. As variáveis dos indicadores "Produção, valorização e destino final dos Resíduos sólidos Urbanos", "Biodiversidade/proteção dos ecossistemas" e "Qualidade do ar" mostram, claramente, essa dura realidade Macapá, com uma pontuação que oscila entre 0 e 34,40 pontos. Estas pontuações assinalam também a pouca importância que se atribui à componente ambiental, como se o que não se vê não mereça a atenção das entidades gestoras da cidade. Se considerarmos, por exemplo, a Política Nacional dos Resíduos Sólidos (PNRS), consegue-se perceber que o município não está, ainda, a preparar-se cabalmente para apresentar uma solução cabal para esta questão, sobremaneira relevante para a vida da cidade: persistem os lixões, não existe sequer um aterro sanitário, apenas um controlado, a reciclagem é praticamente inexistente, tal como a valorização dos resíduos, através da produção de energia ou da reciclagem ou do aproveitamento dos resíduos orgânicos para adubos, através da compostagem. Enfim, ainda não existe um plano municipal dos resíduos sólidos como exige a PNRS.

As maiores pontuações pertencem às dimensões sociocultural e econômica, respectivamente com 61,94 e 60,49 pontos. Relativamente à dimensão econômica entende-se a pontuação relativamente elevada, pouco acima dos 60 pontos, pontuação base da classe "aceitável" (fig. 1). Trata-se da capital do estado, por conseguinte, com dinâmica econômica mais intensa, ao nível da geração de emprego e renda e dos investimentos.

Já na dimensão sociocultural, com 61,94 pontos, o cenário muda um pouco. Relativamente à educação, por exemplo, o município tem pontuações elevadas, assim como tem na questão do gênero, na habitação e na cultura. Sem entrar em mais detalhes, entende-se que estas pontuações altas se devem ao fato de Macapá 


\section{Periódica Eletrânica

ser capital de estado, por conseguinte, com maior oferta ao nível da saúde, educação, cultura e habitação.

\section{CONSIDERAÇÕES FINAIS}

A primeira das considerações que podemos tecer sobre Macapá ser ou não sustentável é a de que a pontuação que obtivemos para Macapá é muito baixa, se consideramos que é uma cidade média e, portanto, onde os problemas podem ser mais facilmente gerenciados. Com uma pontuação média de 48,08 pontos, percebese o muito que há ainda a fazer para melhorar o seu desempenho, em particular nas dimensões ambiental e político institucional.

As baixas pontuações obtidas assinalam que em vários âmbitos as ações dos governos locais, regional e nacional têm de ser revistas. Neste sentido, estes resultados sugerem que as políticas locais e estaduais devem refletir a sustentabilidade, com ações práticas que a promovam, sob pena de estes resultados se acentuarem negativamente, num futuro não muito longínquo. Do mesmo modo, permitem inferir, ainda que indiretamente, que o planejamento e a participação devem ser práticas do cotidiano da gestão municipal e estadual, o que nem sempre acontece, acabando por acentuar ainda mais os resultados negativos.

Quando, praticamente, 3/4 do estado é território protegido, percebe-se que a sustentabilidade pode ser uma aliada poderosa na manutenção e preservação dos recursos naturais do estado. Do mesmo modo, poderá ser a alavanca de um território, cujo desenvolvimento de gênese endógena sustentaria um modelo de desenvolvimento próximo da sustentabilidade, isto é, próximo das aspirações e anseios da população combinados com a preservação da natureza, capitalizando mais cabalmente os recursos do território amapaense e beneficiando mais sua população.

A baixa pontuação da dimensão ambiental corrobora com as afirmações acima tecidas: faz-se mister incorporar a componente ambiental nas políticas públicas e olhar para o ambiente como uma potencialidade e não como uma fatalidade. Faz-se necessário compreender que o ambiente, como um todo, é um elemento importantíssimo para um processo de desenvolvimento que se quer integrado, includente e sustentável, o que exige, a nosso ver, uma aliança tripartida 


\section{Periódica Eletrânica

entre as entidades públicas, as empresas e a sociedade civil organizada, em busca de consensos, de prioridades e de uma visão comum, elementos sem os quais a sustentabilidade não poderá ser implementada.

Por tudo o que foi referido, percebe-se que a avaliação da sustentabilidade pode ser um instrumento que, aliado aos relatórios de sustentabilidade municipal (pesquisa a desenvolver), pode ser de relevante importância para sustentar, informar e promover novas políticas que ajustem o modelo de desenvolvimento. Neste encalço, se entende que o resultado desta avaliação pode ser aprofundado, observando atentamente o comportamento de cada variável, indicador e dimensão, inclusive em datas diferentes para poder perscrutar a evolução desses valores.

Por fim, pelo que foi apresentado neste artigo, percebe-se que Macapá não é sustentável. Confrontando os resultados deste artigo com a vivência in loco, percebe-se que as questões do ambiente, por exemplo, são sistematicamente negligenciadas, não somente a questão referida dos resíduos sólidos urbanos, mas igualmente a ocupação das áreas de ressaca, a poluição das águas e o seu desperdício, etc. É, pois, imperioso pensar a cidade de forma integrada e integradora.

\section{REFERÊNCIAS}

BECKER, Bertha K. Revisão das políticas de ocupação da Amazônia: é possível identificar modelos para projetar cenários? Parcerias Estratégicas, 12 - setembro, 2001, p. 135-159.

BELLEN, Hans M. van. Desenvolvimento Sustentável: uma descrição das principais ferramentas de avaliação. Ambiente \& Sociedade, Vol. VII, N. 1, Jan./Jun., 2004, p. 67-87.

BOFF, Leonardo. Sustentabilidade: o que é - o que não é. Petrópolis, Editora Vozes, 2ª Ed., 2013.

BOSSEL, Hartmut. Indicators for Sustainable Development: theory, methods, applications. A report to the Balaton Group. Winnipeg, IISD, 1999.

BRAGA, Tânia M. et al. Índices de sustentabilidade municipal: o desafio de mensurar. Nova Economia, 14 (3), Setembro-Dezembro, 2004.

COMISSÃO MUNDIAL SOBRE MEIO AMBIENTE E DESENVLVIMENTO (CMMAD). Nosso futuro comum. $2^{\mathrm{a}}$ edição. Rio de Janeiro: Editora FGV, 1991.

FERREIRA, José F. C. A Sustentabilidade do Alto Douro Vinhateiro: realidade ou utopia? Contributo para a avaliação e melhoria da sustentabilidade da região. Tese (Doutorado em Geografia e Planeamento Regional), Faculdade de Ciências Sociais e Humanas (UNL), Lisboa, 2012. 


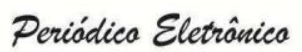

Avaliação da Sustentabilidade: Limites e Possibilidades no Alto Douro Vinhateiro, Portugal. Revista Sustentabilidade em Debate - Brasília, V. 4, n. 2 p. 168-193, jul/dez, 2013.

GIBSON, Robert B. et al. Sustainability Assessment. Criteria and Processes. London: Earthscan, 2005.

HARDI, Peter et al. Models and Methods of measuring Sustainable Development performance. Winnipeg: IISD, 1995.

KERK, Guert van; MANUEL, Arthur R. A comprehensive index for a sustainable society: The SSI - the Sustainable Society Index. Ecological Economics, 66, 2008, p. 228-242.

MASCARENHAS, André et al. The role of common local indicators in regional sustainability assessment. Ecological Indicators, 10, 2010, p. 646-656.

MORAN, Daniel et al. Measuring sustainable development - Nation by Nation. Ecological Economics, 64, 2008, p. 470-474.

NADER, Manal R. et al. Environment and sustainable development indicators in Lebanon: A practical municipal level approach. Ecological Indicators, 8, 2008, p. 771-777.

NASCIMENTO, Durbens M.; COUTO, Aiala C. O.; FERREIRA, Aurilene dos S. Estado, fronteira e redes na Amazônia: uma contribuição ao debate. In: PORTO, Jadson Luís Rebelo; NASCIMENTO, Durbens M. (Orgs.). Interações fronteiriças no Platô das Guianas: Novas construções, novas territorialidades. Rio de Janeiro, Publit, 2010, vol. 1, p. 17-44.

PORTO, Jadson L. R. A Condição Periférico-Estratégica da Amazônia Setentrional: A inserção do Amapá no Platô das Guianas. In: PORTO, Jadson L. R.; NASCIMENTO, Durbens M. (Org.). Interações Fronteiriças no Platô das Guianas: Novas construções, novas territorialidades. 1 ed., Rio de Janeiro Publit, 2010, v. 1, p. 139-160.

et al. A Reformatação da Fronteira Amapaense: das políticas públicas aos planos diretores e ambientais. In: PORTO, Jadson L. R. Reformatações fronteiriças no platô das Guianas: (re) territorialidades de cooperação em construção. Rio de Janeiro: Publit, v. 1, 2011, p. 2149.

PROGRAMA CIDADES SUSTENTÁVEIS. Metas de Sustentabilidade para os Municípios Brasileiros (Indicadores de Referência), 2012. Disponível em: www.cidadessustentaveis.org.br. Última Consulta em: 10-05-2014.

RAMOS, Tomás B. Development of regional sustainability indicators and the role of academia in this process: the Portuguese practice. Journal of Clean Production, 17, 2009, p. 1101-1115.

RIBEIRO, Adagenor L. Modelo de indicadores para mensuração do desenvolvimento sustentável na Amazônia. Tese (Doutorado em Engenharia de produção), UFPA/NAEA/PDTU, Belém-PA, 2002.

ROLDÁN, Adrián B.; VALDÉS, Américo S. Proposal and application of a Sustainable Development Index. Ecological Indicators, 2, 2002, p. 251-256.

SANTOS, Daniel et al. Índice de Progresso Social na Amazônia Brasileira. IPS Amazônia 2014. Belém-Pa: Imazon, 2014

SANTOS, Emmanuel R. C. Grandes projetos amazônicos e configuração geográfica do Amapá. In: PORTO, Jadson L. R.; NASCIMENTO, Durbens M. (Org.). Interações Fronteiriças no Platô das Guianas. 1ed. Rio de Janeiro, Publit, 2010, v. 1, p. 45-72.

SELMAN, Paul. Local Sustainability. Managing and Planning Ecologically Sound Places. London, Paul Chapman Publishing, 1996. 


\section{Periódica Eletrânica

da Alta Paulista

\section{Cidades Sustentáveis}

SIENA, Osmar. Método para avaliar o progresso em direção ao desenvolvimento sustentável. Tese (Doutorado em Engenharia de Produção), Universidade Federal de Santa Catarina, Florianópolis, 2002.

SILVA, Antônio S. da; SOUZA, José G. de; LEAL, Antônio C. Qualidade de vida e meio ambiente: experiência de consolidação de indicadores de sustentabilidade em espaço urbano. Revista Sustentabilidade em Debate - Brasília, V. 3, n. 2 p. 177-196, jul/dez, 2012.

SILVA, Christian L. (Org.). Desenvolvimento Sustentável. Um Modelo analítico integrado e adaptativo. Petrópolis, Editora Vozes, 2006.

SOUZA, Ana C. M. Análise do planejamento urbano de um espaço em transformação: as cidades de Macapá e Santana na perspectiva do desenvolvimento local. Dissertação (Mestrado em Desenvolvimento Regional), Universidade Federal do Amapá, Macapá, 2014.

SUPERTI, Eliane; PORTO, Jadson L. R.; MARTINS, Carmentilla das C. Políticas públicas de integração física da Amazônia e a fronteira internacional do Amapá. Anais do I Circuito de Debates Acadêmicos. IPEA 47, Code 2011, p. 13.

TAVARES, Everkley M. F. Avaliação de políticas públicas de desenvolvimento sustentável: dilemas teóricos e pragmáticos. Holos, Ano 21, maio/2005, 120-129.

TOSTES, José A. Transformações urbanas das pequenas cidades amazônicas (AP) na faixa de fronteira setentrional. Rio de Janeiro, Publit, 2011.

Práticas urbanas intervencionistas nas cidades amazônicas: no Amapá, a encruzilhada entre a necessidade e a obrigação. XII Encontro da Associação Nacional de PósGraduação e Pesquisa em Planejamento Urbano Regional, 21 a 25 de Maio de 2007, Belém Pará, 2007.

VEIGA, José E. Desenvolvimento Sustentável, o desafio do século XXI. $3^{\text {a }}$ Edição. Rio de Janeiro: Garamond Universitária, 2008.

WHEELER, Stephen. Planning for Sustainability. Creating livable, equitable, and ecological communities. Oxon: Routledge, 2004. 